\title{
Evaluation of Self Consolidating Steel Fibre Concrete (SCSFRC) \& Its Fresh Properties
}

\author{
Dr.G.Elangovan and Mr.V.K.Ashok kumaravel
}

\begin{abstract}
Superior performances of Self-Compacting Concrete (SCC) in fresh state to achieve a more uniform distribution encourage the addition of fibers in concrete which is a motivation for structural application of fibre reinforced concrete. Steel fibre used in the Self Consolidating Steel Fibre concrete (SCSFRC) is to enrich the performance of the concrete material. But SCC has intrinsic low ductility and poor toughness which restrict the fields of application of SCC. The disadvantage of SCC can be avoided by reinforcing with randomly distributed discontinuous fibers. Traditionally rational mix design method is available for SCC which make tedious to obtain the self compacting properties in various mix proportion of concrete. The mix design is based on principle of limiting range for total aggregate volume and coarse aggregate volume in concrete. It forms the basis for the concrete to be flowable and to achieve high workability. This paper focus on the design mix for SCSFRC, mix design principle and experimental investigation carried out on Self Consolidating Steel Fibre Reinforced Concrete (SCSFRC) fresh properties.

Keywords: SCSFRC Constituents, Mix design Principle, Applications-SCSFRC.
\end{abstract}

\section{Introduction:}

Concrete is a composite material. The complexity of concrete design arises with the addition of material to normal concrete. It leads to change in all properties of concrete such as compressive strength, tensile strength, stress-strain relationship, flexural strength, flexural rigidity, creep, shrinkage, corrode properties, permeability etc. Hence a good concrete must satisfy both fresh and hardened properties.

\section{SCSFRC}

Self Consolidating Steel Fibre Reinforced Concrete (SCSFRC) is a composite material whose components include the traditional constituents of Portland cement concrete (hydraulic cement, fine and coarse aggregates, admixtures...) and a dispersion of randomly oriented short discrete steel fibres.

Self-compaction (SC) property of concrete is able to flow and consolidate on its own due to high workability and gravitational effect. At the same time it is cohesive to fill spaces of almost any size and shape without segregation or bleeding. The uniformity in mix of concrete is also attained. SC's unique properties give it significant economic, constructability and aesthetic performance on conventional projects.

\section{CONSTITUENTS OF SCSFRC MIX DESIGN}

\section{SCSFRC $=$ SELF COMPACTION (SC) + STEEL FIBRE}

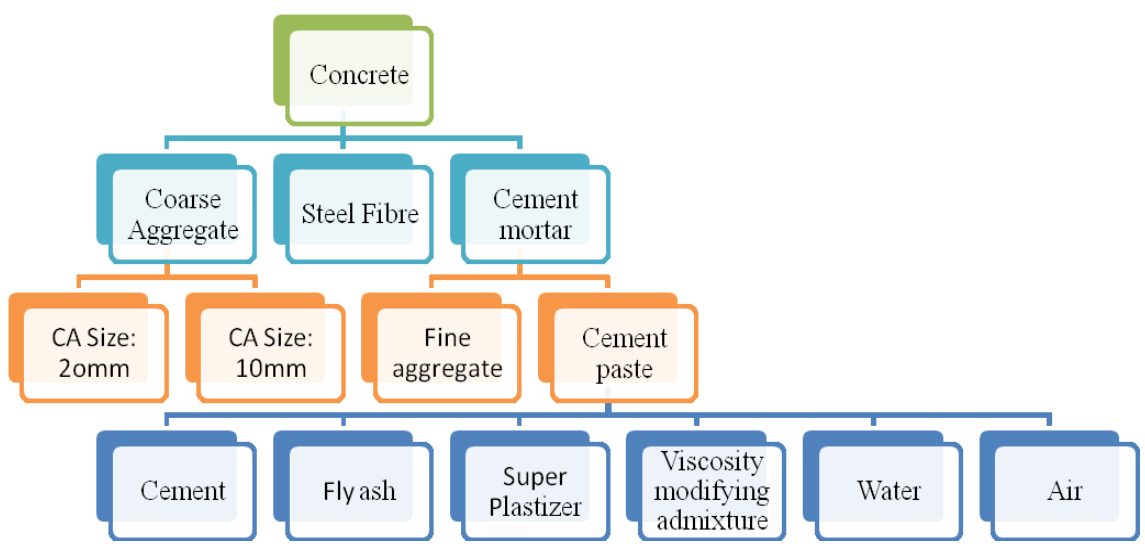

\section{FUNCTIONS OF CONSTITUENTS}

The following unique functions are performed by the materials in the concrete to achieve fresh and hardened properties. 
Cementitious Material - Cement \& Fly ash.

Cement - Binding material and Strength of concrete.

Fly ash - Class F - Reduce heat of hydration of cement, Increase flowability and High sulphate resisting.

Coarse aggregate size $20 \mathrm{~mm} \mathrm{\&} 10 \mathrm{~mm}$ - Inert material but presence imparts physical strength.

Fine aggregate - Sand or artificial sand (M Sand) -Inert material but presence imparts physical strength.

Steel Fibre - Increase flexural properties.

Water - Workability \& Initiate chemical reaction of cementitious material.

Water reducing Admixture - Super plastizer - reduce w/c ratio.

Viscosity Modifying Admixture - To increase the flowable property of concrete.

Air - needed for durability, improve the viscosity of a mix and increase the paste volume, but may adversely affect paste density.

What is mix design?

A mix design methodology includes suitable selection and proportioning of raw materials and other constituents to achieve the required level of material performance, both in the fresh and hardened state.

\section{PROPOSED MIX DESIGN FOR EXPERIMENTAL INVESTIGATION}

Table Coarse aggregate 30 percent \& fibre content 0.25 percent of volume of SCSFRC concrete

\begin{tabular}{|c|c|c|c|c|c|c|}
\hline $\begin{array}{l}\text { SL. } \\
\text { NO. }\end{array}$ & Mix ID. & $\begin{array}{c}\text { Total } \\
\text { Aggregate } \\
\text { Volume (\%) }\end{array}$ & $\begin{array}{c}\text { Coarse } \\
\text { aggregate } \\
\text { Volume } \\
\left(\text { litre/m } / \mathbf{m}^{3}\right)\end{array}$ & $\begin{array}{c}\text { Fine } \\
\text { Aggregate } \\
\text { Volume } \\
\left(\text { litre } / \mathbf{m}^{3}\right) \\
\end{array}$ & $\begin{array}{c}\text { Cement Paste } \\
\text { Volume } \\
\text { (litre } / \mathbf{m}^{3} \text { ) }\end{array}$ & $\begin{array}{c}\text { Fibre } \\
\text { Volume } \\
\left(\text { litre } / \mathbf{m}^{3}\right)\end{array}$ \\
\hline 1. & ID5530(0.5) & 55 & 300 & 250 & 445 & 5 \\
\hline 2. & ID6530(0.5) & 65 & 300 & 350 & 345 & 5 \\
\hline 3. & ID7030(0.5) & 70 & 300 & 400 & 295 & 5 \\
\hline 4. & ID7530(0.5) & 75 & 300 & 450 & 245 & 5 \\
\hline
\end{tabular}

\begin{tabular}{|c|c|c|c|c|c|c|}
\hline \multicolumn{7}{|c|}{ Total Volume of concrete $=\mathrm{CA}+\mathrm{FA}+\mathrm{CP}+\mathrm{FV}=1000$ litre $/ \mathrm{m}^{3}$} \\
\hline $\begin{array}{l}\text { SL. } \\
\text { NO }\end{array}$ & Mix ID. & $\begin{array}{c}\text { Total Aggregate } \\
\text { Volume (\%) }\end{array}$ & $\begin{array}{c}\text { Coarse } \\
\text { aggregate } \\
\text { Volume } \\
\left(\text { litre } / \mathbf{m}^{3}\right)\end{array}$ & $\begin{array}{c}\text { Fine } \\
\text { Aggregate } \\
\text { Volume } \\
\text { (litre } / \mathbf{m}^{3} \text { ) }\end{array}$ & $\begin{array}{c}\text { Cement } \\
\text { Paste } \\
\text { Volume } \\
\text { (litre } / \mathbf{m}^{3} \text { ) }\end{array}$ & $\begin{array}{c}\text { Fibre } \\
\text { Volume } \\
\text { (litre } / \mathbf{m}^{3} \text { ) }\end{array}$ \\
\hline 1. & ID5530(0.25) & 55 & 300 & 250 & 447.5 & 2.5 \\
\hline 2. & ID6530(0.25) & 65 & 300 & 350 & 347.5 & 2.5 \\
\hline 3. & ID7030(0.25) & 70 & 300 & 400 & 297.5 & 2.5 \\
\hline 4. & ID7530(0.25) & 75 & 300 & 450 & 247.5 & 2.5 \\
\hline
\end{tabular}

Table Coarse aggregate 40 percent \& fibre content 0.25 percent of volume of SCSFRC concrete

\begin{tabular}{|c|c|c|c|c|c|c|}
\hline $\begin{array}{l}\text { SL. } \\
\text { NO }\end{array}$ & Mix ID. & $\begin{array}{c}\text { Total } \\
\text { Aggregate } \\
\text { Volume (\%) }\end{array}$ & $\begin{array}{c}\text { Coarse } \\
\text { aggregate } \\
\text { Volume } \\
\left(\text { litre } / \mathbf{m}^{3}\right)\end{array}$ & $\begin{array}{c}\text { Fine } \\
\text { Aggregate } \\
\text { Volume } \\
\left.\text { (litre } / \mathbf{m}^{3}\right)\end{array}$ & $\begin{array}{c}\text { Cement } \\
\text { Paste } \\
\text { Volume } \\
\text { (litre } / \mathbf{m}^{3} \text { ) }\end{array}$ & $\begin{array}{c}\text { Fibre } \\
\text { Volume } \\
\left(\text { litre } / \mathbf{m}^{3} \text { ) }\right.\end{array}$ \\
\hline 1. & ID5540(0.25) & 55 & 400 & 150 & 447.5 & 2.5 \\
\hline 2. & ID6540(0.25) & 65 & 400 & 250 & 347.5 & 2.5 \\
\hline 3. & ID7040(0.25) & 70 & 400 & 300 & 297.5 & 2.5 \\
\hline 4. & ID7540(0.25) & 75 & 400 & 350 & 247.5 & 2.5 \\
\hline
\end{tabular}

Table Coarse aggregate 30 percent $\&$ fibre content 0.5 percent of volume of SCSFRC concrete

\section{INFERENCE OF FRESH PROPERTIES}

TableObservations of slump test value (mm)

\begin{tabular}{|c|c|c|c|}
\hline Mix ID & $30(0.25)$ & $40(0.25)$ & $30(0.5)$ \\
\hline ID55 & 47 & 54 & 32 \\
\hline ID65 & 77 & 86 & 99 \\
\hline ID70 & 93 & 110 & 118 \\
\hline ID75 & 0 & 0 & 0 \\
\hline
\end{tabular}




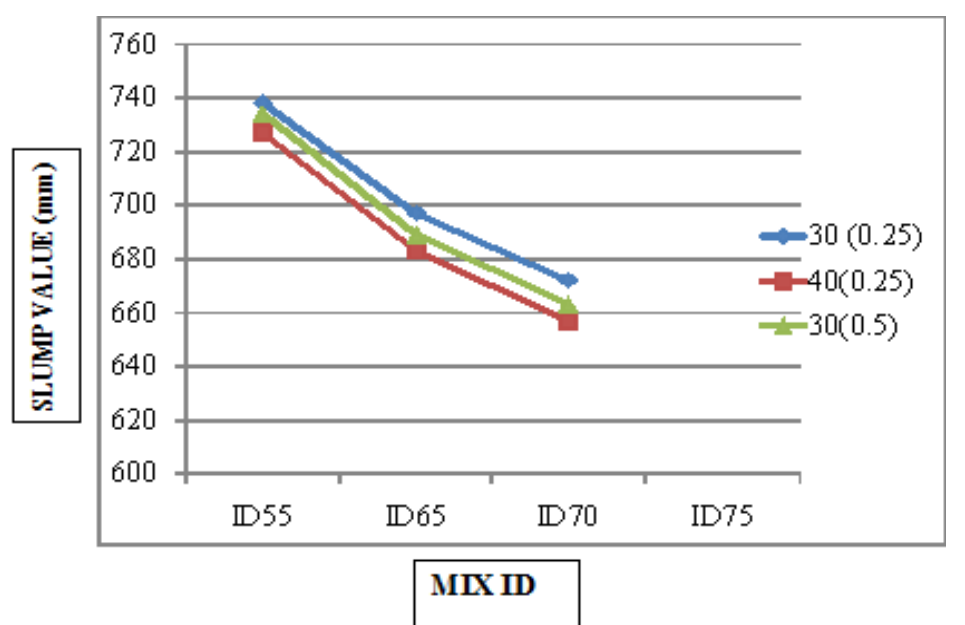

Fig. Slump test value (mm) - Mix ID vs. Slump value (mm). Table Observations of Total spread time $T_{50}$ value (s)

\begin{tabular}{|l|l|l|l|}
\hline Mix ID & $30(0.25)$ & $40(0.25)$ & $30(0.5)$ \\
\hline ID55 & 738 & 727 & 734 \\
\hline ID65 & 697 & 683 & 689 \\
\hline ID70 & 672 & 657 & 663 \\
\hline ID75 & 0 & 0 & 0 \\
\hline
\end{tabular}

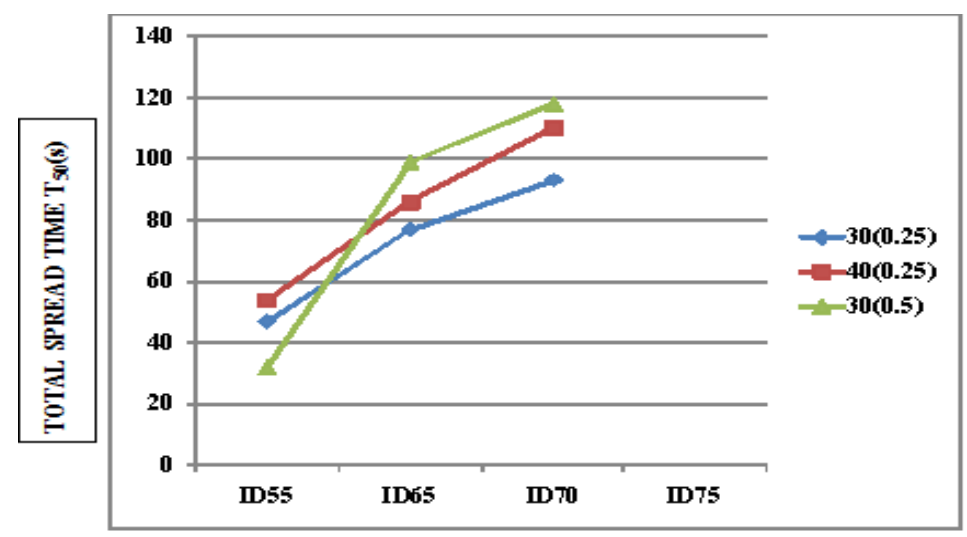

\section{ID}

Fig. Total spread time value $T_{50}(s)-M i x ~ I D ~ v s . ~ T_{50}$ value (s)

The fresh properties of SCSFRC cannot be achieved formix proportions contain total aggregate 75 percent volume of concrete and above it. But if the range of total aggregate is below 70 percent volume of concrete it is easy to obtain the fresh properties with minimum content of admixture and water cement ratio. That is minimum cement paste volume in the concrete should not be below 30 percent volume of concrete. The increase in cement paste volume (cement content) will make the concrete to perform both fresh and hard state of concrete well. Then also maintaining the volume of coarse aggregate below 50 percent in concrete is mandatory so that the flowability can achieved. Thus the mix design is done according to optimum constituents of concrete will able enable the concrete to be flowable.

\section{DESIGN PRINCIPLE}

Self consolidation of concrete is induced with the properties of self compaction, low water cement ratio and fibre content of concrete. The properties of Self compaction will leads high workability and uniformity of mix. 
Self compaction is incorporated by volume of coarse aggregate less than 50 percent volume of concrete and total volume of aggregate in the range of 55 to 70 percent volume of concrete i.e. minimum volume of cement paste not less than 30 percent volume of concrete.

The fibre content imparts toughness and tensile strength of concrete. The fibre content should be on basis of aspect ratio in which length of fibre should less of $5 \mathrm{~mm}$ from minimum spacing of reinforcement bar in the member. This is to maintain passing ability of SCSFRC.

\section{EXPLAINATIONS}

The mix design is done on the basis of proportionate the constituents of concrete with respect to the fresh and hardened properties.

In SCSFRC the mix design is done for fresh properties to achieve flowable and highly workable of concrete by reducing the coarse aggregate volume as well enriches the cement paste volume in concrete. Other fresh properties include achieving the uniformity in distribution of random discrete steel fibre and passing ability according to size of constituents of concrete with respect to the spacing of reinforcement in RCC member.

Next the hardened properties include proportionate the constituents according cement content and water cement ratio. The high cement aggregate ratio will increase compressive strength but dry shrinkage to be control. Hence the use of steel fibre maintains the stress developed due to dry shrinkage and arrests the cracks which arise in concrete.

The admixture in the concrete plays an important role in both the fresh and hardened properties. The highly flowable and viscosity properties of admixture will increase the fresh properties of SCSFRC without increase the water content in concrete. The reduce water cement ratio of concrete also increases the strength of concrete.

\section{APPLICATIONS OF SCSFRC \\ Structural}

D Ductility ratio of concrete can be increased.

Span length between columns of the structure can be increased.

- Tensile strength of concrete can be incorporated in design make economic in reinforcement design.

Jacketing of pipe, patch repair in concrete structures mostly where the tensile strength to be increased and rebar meshing not possible.

- High cement to aggregate ratio in concrete will cause dry shrinkage can be controlled by steel fibre.

- Column which is eccentric loaded the SCSFRC can be next to the kernel section that is in the tensile zone.

- Simply supported beam below the neutral axis of tensile zone and above which minimum fibre content of SCSFRC.

\section{Construction}

High slump concrete needed for pump concrete, long column, retaining wall, pile foundations and congested reinforcement member.

\section{Conclusion}

This paper brings a conclusion to mix design of SCSFRC concrete i.e. proportionate according to the need of fresh and hardened properties of concrete. It also emphasis onachieving the fresh and hardened properties if mix design will be based on functions of constituents and economic of design could be achieved.

The mix design should constraint to the total volume of aggregate range in concrete between 55 to 70 percent volume of concrete and also the volume of coarse aggregate should below 50 percent volume of concrete i.e. minimum 30 percent cement paste volume is needed to achieve SCSFRC. The mix design proportionate the mix in such way to consolidate while fresh state and also increase the ductile property of concrete due to steel fibre. This also makes the concrete uniform in mix with high workability.

\section{FUTURE WORK}

Properties of Self Consolidating Fibre reinforced concrete (SCFRC) can be studied by varying type and content of discontinuous random discrete fibre such as polypropylene, glass fibre, hybrid fibre etc. 


\section{Reference}

[1]. Hajime Okamura and Masahiro Ouchi (April 2003) "Self Compacting Concrete" - Journal of Advanced Concrete Technology, Japan Concrete Institute Vol 1 No. 1. pp 5-15

[2]. C. Parra, M. Valcuende, F. Gomez (2010) "Splitting tensile strength and modulus of elasticity of self-compacting concrete",Journal home page at Science direct.

[3]. M.Ramali and E.T. Dawood (2011) "Effect of Steel Fibres on the Engineering performance of Concrete", Asian Journal of Applied Science, Malaysia.

[4]. K. Turk, P. Turgut, M. Karatas, A. Benli ( September 2010 ) "Mechanical Properties of Self-compacting Concrete with Silica Fume/Fly Ash" 9th International Congress on Advances in Civil Engineering, Karadeniz Technical University, Trabzon, Turkey, pp 27-30.

[5]. "Specification and Guidelines for Self-Compacting Concrete" - EFNARC. 